\title{
Stromal fibroblasts are predictors of disease-related mortality in esophageal squamous cell carcinoma
}

\author{
SHIN SAITO $^{1}$, KAZUE MORISHIMA $^{1}$, TAKASHI UI $^{1}$, DAISUKE MATSUBARA ${ }^{2}$, TOMOKO TAMURA $^{2}$, \\ SACHIKO OGUNI $^{2}$, YOSHINORI HOSOYA ${ }^{1}$, NAOHIRO SATA ${ }^{1}$, ALAN T. LEFOR ${ }^{1}$, \\ YOSHIKAZU YASUDA ${ }^{1}$ and TOSHIRO NIKI ${ }^{2}$
}

Departments of ${ }^{1}$ Surgery and ${ }^{2}$ Integrative Pathology, Jichi Medical University, Shimotsuke-City, Tochigi 329-0498, Japan

Received March 27, 2014; Accepted April 28, 2014

DOI: $10.3892 /$ or.2014.3216

\begin{abstract}
The growth, invasiveness and metastasis of human cancers are determined not only by cancer cells, but also by their microenvironment. Activated stromal fibroblasts promote tumor progression by secreting growth factors. In the present study, we focused on interrelations between cancer and fibroblasts, the main component of tumor stroma. We retrospectively analyzed the relations of mortality to clinical, pathological, and $\alpha$-smooth muscle actin ( $\alpha$-SMA) characteristics in 97 consecutive patients with esophageal squamous cell carcinoma (ESCC). In vitro, we used TE-11, KYSE150 and KYSE220 ESCC cell lines and isolated esophageal stromal fibroblasts, some of which were immortalized.Migration assays were conducted to assess the effects of fibroblasts on cancercell migration and 3-dimensional organotypic cultures. In vivo, TE-11 and KYSE220 cells plus immortalized fibroblasts were co-transplanted subcutaneously in Nod/Scid mice to assess the effects of fibroblasts on tumorigenicity. Clinicopathologically, the $\alpha$-SMA expression of cancer stroma was correlated with venous invasion $(\mathrm{p}<0.01)$, nodal involvement $(\mathrm{p}=0.02)$, recurrence $(\mathrm{p}=0.01)$, and was a predictor of survival in patients with stage I and II ESCC ( $\mathrm{p}=0.04)$. In vitro, the presence of fibroblasts strongly promoted the migration of TE-11, KYSE150 and KYSE220 cells. On organotypic culture, stromal invasion was observed only in the presence of immortalized fibroblasts. In vivo, tumors developed or grew in a fibroblast-dependent manner after implantation. Our findings provide evidence that stromal fibroblasts and tumor cells interact to promote tumor progression in ESCC. In patients with earlier stage ESCC, $\alpha$-SMA may be a predictor of mortality. Inhibition of paracrine systems associated with tumor fibroblasts may slow or reverse tumor progression, potentially leading to the development of new targeted therapies.
\end{abstract}

Correspondence to: Professor Toshiro Niki, Department of Integrative Pathology, Jichi Medical University, 3311-1 Yakushiji, Shimotsuke-City, Tochigi 329-0498, Japan

E-mail: tniki@jichi.ac.jp

Key words: esophageal cancer, SMA, stroma, myofibroblast, prognosis

\section{Introduction}

Worldwide, esophageal cancer is the sixth leading cause of cancer-related mortality (1). Squamous cell carcinoma (SCC) is the predominant histologic type of esophageal cancer worldwide (2), and esophageal squamous cell carcinoma (ESCC) is often encountered in Asia (3-5), including Japan. ESCC is one of the least studied and most fatal cancers (6).

The microenvironment of cancer cells has recently been shown to strongly influence the biologic properties of cancer (7). In fact, tumors consist of tumor cells, fibroblasts, endothelial cells, immune cells and extracellular matrix. In addition, many types of solid tumors contain smooth muscle actin (SMA)-positive myofibroblasts [i.e., activated fibroblasts, peritumor fibroblasts, and carcinoma-associated fibroblasts (CAFs)] within the stroma (8). Molecular features thought to influence outcomes are generally related to the characteristics of carcinoma cells (9); however, it has become increasingly apparent that the components of the tumor stroma play an important role in promoting tumor progression $(10,11)$. Myofibroblasts have been reported to be related to poor outcomes in several types of carcinoma (12-14). Fibroblasts are associated with cancer cells at all stages of disease progression, and their production of growth factors, chemokines, and extracellular matrix facilitates the angiogenic recruitment of endothelial cells and pericytes (15).

Marsh et al reported that an SMA-positive myofibroblastic stroma is the strongest predictor of mortality in patients with oral SCC (9). In the present study, we focused on the complex interrelations between ESCC cells and fibroblasts, the main component of cancer stroma. The levels of $\alpha$-smooth muscle actin ( $\alpha$-SMA) were determined immunohistochemically in ESCC lesions, and immunoreactivity was observed in stromal fibroblasts. We also prepared in vitro and in vivo experimental systems to evaluate interactions between ESCC and fibroblasts.

\section{Materials and methods}

Tissue collection and processing. From January 1st 2001 to December 31st 2010, a total of 347 patients underwent resection of ESCC in Jichi Medical Hospital. We identified and studied patients with tumor invasion beyond the muscularis mucosa who received neither preoperative chemotherapy nor 
radiotherapy. We then retrospectively analyzed the relations of clinical, pathological and molecular ( $\alpha$-SMA and vimentin) features to outcomes in 97 patients with ESCC. Data were collected on age, gender, tumor stage $(16,17)$, outcomes, the presence or absence of recurrence, lymph node metastasis, depth of tumor invasion, and the presence or absence of venous invasion.

Immunohistochemistry (IHC). Representative paraffin blocks were selected, and tissue sections (4- $\mu \mathrm{m}$ thick) of the specimens were deparaffinized in xylene, rehydrated in a graded series of alcohol, and transferred to phosphate-buffered saline (PBS). The slides were stained immunohistochemically for $\alpha$-SMA and vimentin according to conventional protocols. The antibodies used were $\alpha$-SMA (clone 1A4) and vimentin (clone V9) (both from Dako, Ely, UK). $\alpha$-SMA was scored according to the extent of stromal positivity as low $(<5 \%$ stroma stained positive), moderate (patchy/focal expression, $5-50 \%$ stroma stained positive) or high (diffuse expression throughout tumor, $>50 \%$ stroma stained positive) (Fig. 1) (9). In addition to $\alpha$-SMA, vimentin immunostain was used as an ancillary method to help identify stromal fibroblasts.

Cell lines and media. We used three ESCC cell lines and esophageal stromal fibroblasts. TE-11 was purchased from RIKEN Cell Bank (Tsukuba, Japan). KYSE150 and KYSE220 were purchased from Health Science Research Resources Bank (Osaka, Japan). All cancer cell lines were maintained in RPMI-1640 supplemented with $10 \%$ fetal bovine serum (FBS; Autogen-Bioclear, Wiltshire, UK), glutamine, $100 \mathrm{U} / \mathrm{ml}$ penicillin and $100 \mu \mathrm{g} / \mathrm{ml}$ streptomycin, in a humidified atmosphere of $5 \% \mathrm{CO}_{2}$ and $95 \%$ air. These three cell lines were selected from among 22 ESCC cell lines on the basis of the results of cell proliferation induced by fibroblast supernatant (unpublished observation). Primary human esophageal fibroblasts designated as HEF75 were isolated from normal human esophageal tissue specimens resected surgically in the Department of Surgery, Jichi Medical Hospital. The patients had not received any neoadjuvant chemotherapy or radiotherapy irradiation. The study was approved by the Jichi Medical University Ethics Committee, and written informed consent was obtained from the patients.

To isolate fibroblasts $(18,19)$, the epithelial tissue was washed twice in PBS and cut into 1- to $2-\mathrm{mm}^{3}$ pieces. A couple of pieces were placed into the well of a 6 -well plate. The explants were cultured for $48 \mathrm{~h}$ in Dulbecco's Modified Eagle's Medium (DMEM; Invitrogen) supplemented with $10 \% \mathrm{FBS}$, antibiotics, and glutamine at $37^{\circ} \mathrm{C}$ in a humidified atmosphere of $5 \% \mathrm{CO}_{2}$ and $95 \%$ air. After removing the explants and the non-adherent cells, the remaining cells were incubated for 1 to 2 weeks. The adherent cells were then trypsinized and passaged into a new culture flask at a ratio of 1:3 for further expansion. The cells were used for subsequent experimental studies at the third passage. Some of the human esophageal fibroblasts were immortalized. Briefly, to induce cell immortalization, transforming DNA (pCLXSN-hTERT and pVSV-G) was added to competent cells (Escherichia coli), which were then spread on LB plates and incubated at $37^{\circ} \mathrm{C}$ to produce colonies. Next, in accordance with the Qiagen Plasmid Midi/Maxi kit (Qiagen KK, Tokyo, Japan) protocol, bacterial
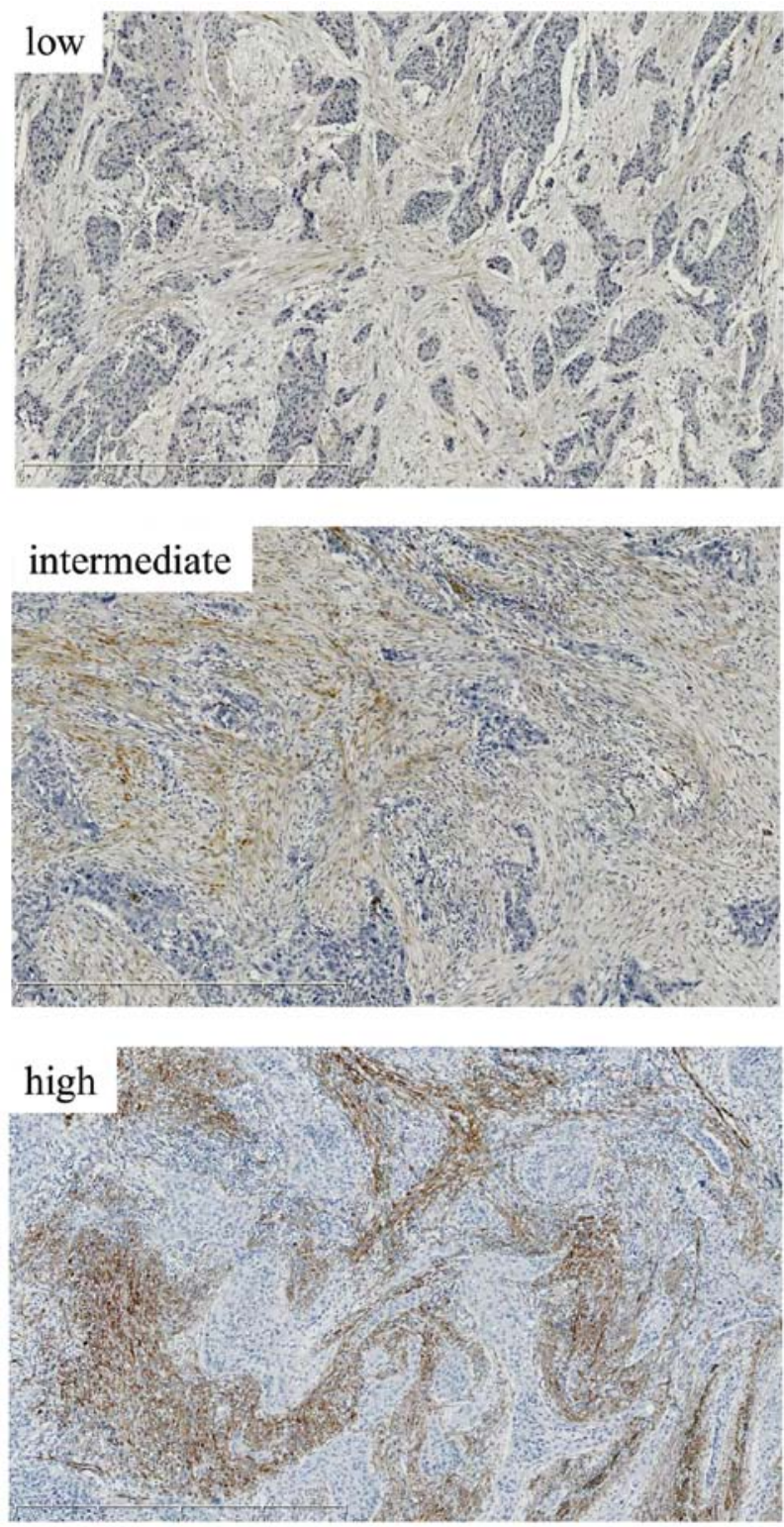

Figure 1. $\alpha$-SMA immunohistochemistry. $\alpha$-SMA immunostained sections of esophageal squamous cell carcinoma (ESCC). Representative images of ESCC with low $\alpha$-SMA expression, intermediate $\alpha$-SMA expression, and high $\alpha$-SMA expression in stroma are shown. $\alpha$-SMA, $\alpha$-smooth muscle actin.

cells were collected from the LB plate colonies. Plasmid DNA was eluted from the bacterial pellets. The concentration of DNA was adjusted to $1.0 \mu \mathrm{g} / \mu \mathrm{l}$. The two DNA products were digested by adding the restriction enzymes HindIII and EcoRI, and $1 \%$ agarose gel electrophoresis was performed to confirm that pVSV-G was cut with EcoRI.

In accordance with the protocol of Lipofectamine 2000 reagent (Invitrogen Co., Ltd.), plasmid DNA was transfected into GP2-293 cell line. After $48 \mathrm{~h}$, the culture supernatant including the retrovirus was added to fibroblasts to induce transduction. Selection was performed with G418 (Geneticin ${ }^{\circledR}$; Invitrogen) $48 \mathrm{~h}$ after transduction. In the present study, cells between the 20 and 25 th passages after viral transduction were used. Immortalized human esophageal fibroblasts were designated as human embryonic fibroblast (HEF) 75-human telomerase reverse transcriptase (HEF75-hTERT). 
Migration assay and 3D organotypic culture. Migration and invasion assays were conducted as described previously $(20,21)$. For migration assay, 24-well cell culture inserts with a pore size of $8-\mu \mathrm{m}$ (Falcon) were used. The inserts were placed in a 24-well plate containing medium with HEF75. Cancer cells in

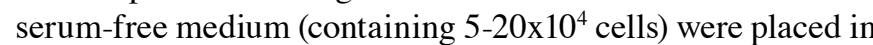
each insert. Migratory cells pass through membrane and cling to the bottom side. After cells remaining on the membrane were removed, migratory cells were stained and captured in 5 different high-power fields. The numbers of migratory cells were then automatically counted with the use of a VH analyzer (Keyence, Osaka, Japan). For invasion assay, HEF75-hTERT fibroblasts were mixed with collagen gel at a concentration of $1 \times 10^{6}$ cells $/ \mathrm{ml}$ and allowed to contract. Then, $2 \times 10^{5}$ of cancer cells were plated, using a cloning ring. The cells were allowed $4 \mathrm{~h}$ to attach to the upper surface of the contracted collagen lattice. The cultures were submerged for 4 days, then subsequently placed into 6-well inserts, raised to an air-liquid interface, and cultured for an additional 10-14 days. The schemata of these experiments are shown in Fig. 2.

Co-injection in Nod/Scid mice. Cancer cells and fibroblasts were co-transplanted subcutaneously in Nod/Scid mice to assess the effects of fibroblasts on tumorigenicity. ESCC cells alone or together with human esophageal fibroblasts (HEF75) were suspended in PBS and injected subcutaneously into the flanks of the mice (two injection sites per mouse). We subcutaneously injected $200 \mu \mathrm{l}$ of a cancer cell suspension with a concentration of $1 \times 10^{6}$ cells $/ \mathrm{ml}$ into the right side of the mice and $200 \mu \mathrm{l}$ of a suspension containing a 1:1 mix of cancer cells $\left(2 \times 10^{6}\right.$ cells $\left./ \mathrm{ml}\right)$ and HEFs $\left(6 \times 10^{6}\right.$ cells $\left./ \mathrm{ml}\right)$ into the left side of the mice. The mice $(n=3)$ were sacrificed 6 weeks after the injections. We measured the minor axis and major axis and calculated the tumor volume as an oval sphere shape. The following formula was used to calculate tumor volume: Volume $=0.5236 \mathrm{ddD}$ (d, minor axis; $\mathrm{D}$, major axis).

Statistical analysis. The primary end point was death from ESCC. Survival time was measured from the date of the surgery until the date of mortality due to ESCC or the date on which the patient was last confirmed to be alive. Data were censored at the time of death for patients who died of causes other than ESCC.

Kaplan-Meier survival curves and log-rank tests were used to assess the statistical significance of differences in survival. Analyses were performed using the JMP 9 statistical software package (SAS Institute Inc., Cary, NC, USA). Pearson's Chi-square test was used to analyze relations between $\alpha$-SMA expression and clinicopathological characteristics. Student's t-test was used to compare differences between 2 groups and to analyze the results of migration assays. Both of these analyses were performed with the use of JMP 9 software. $p<0.05$ was considered to indicate a statistically significant difference.

\section{Results}

$\alpha$-SMA expression is associated with ESCC mortality in stage I and II. During the period from 2001 to 2010, data were available for 97 patients with ESCC. Table I shows the characteristics of these patients. There were 15 women (15.4\%) and 82
Table I. Characteristics of 97 patients with ESCC.

\begin{tabular}{|c|c|c|}
\hline & No. & $\%$ \\
\hline \multicolumn{3}{|l|}{ Age (years) } \\
\hline $40-59$ & 18 & 18.5 \\
\hline $60-79$ & 76 & 78.4 \\
\hline $80-99$ & 3 & 3.1 \\
\hline Average & $67.2 \pm 7.7$ & \\
\hline \multicolumn{3}{|l|}{ Gender } \\
\hline Female & 15 & 15.5 \\
\hline Male & 82 & 84.5 \\
\hline \multicolumn{3}{|l|}{ Recurrence } \\
\hline Present & 34 & 35.1 \\
\hline Absent & 63 & 64.9 \\
\hline \multicolumn{3}{|l|}{ Outcome } \\
\hline AWOD & 62 & 63.9 \\
\hline AWD & 4 & 4.1 \\
\hline DOAD & 1 & 1.1 \\
\hline DOD & 30 & 30.9 \\
\hline \multicolumn{3}{|l|}{ Disease stage ${ }^{a}$} \\
\hline I & 29 & 29.9 \\
\hline II & 32 & 33.0 \\
\hline III & 32 & 33.0 \\
\hline IV & 4 & 4.1 \\
\hline \multicolumn{3}{|l|}{ Disease stage $^{\mathrm{b}}$} \\
\hline $\mathrm{I}(\mathrm{A}, \mathrm{B})$ & $36(29,7)$ & 37.1 \\
\hline II $(\mathrm{A}, \mathrm{B})$ & $26(9,17)$ & 26.8 \\
\hline III (A, B, C) & $31(18,8,5)$ & 32 \\
\hline IV & 4 & 4.1 \\
\hline \multicolumn{3}{|c|}{ Depth of invasion } \\
\hline $\mathrm{T} 1 \mathrm{~b}$ & 44 & 45.4 \\
\hline $\mathrm{T} 2$ & 15 & 15.5 \\
\hline $\mathrm{T} 3$ & 37 & 38.1 \\
\hline $\mathrm{T} 4$ & 1 & 1.0 \\
\hline \multicolumn{3}{|c|}{ Nodal involvement } \\
\hline Present & 51 & 52.6 \\
\hline Absent & 46 & 47.4 \\
\hline \multicolumn{3}{|l|}{$\alpha-\mathrm{SMA}$} \\
\hline Low & 46 & 47.4 \\
\hline Intermediate & 24 & 24.7 \\
\hline High & 27 & 27.8 \\
\hline
\end{tabular}

DOD, died of disease; AWOD, alive without disease; AWD, alive with disease; DOAD, died of another disease. a Japanese Classification of Esophageal Cancer, 10th edition; ${ }^{\text {} T N M ~ C l a s s i f i c a t i o n ~ o f ~ M a l i g n a n t ~}$ Tumours, Union for International Cancer Control, 7th edition. ESCC, esophageal squamous cell carcinoma; $\alpha$-SMA, $\alpha$-smooth muscle actin.

men $(84.5 \%)$. The mean age at surgery ( \pm standard deviation) was $67.2 \pm 7.7$ years (range, $44-82$ years). The median followup was 1,244 days, and the minimum follow-up was 94 days. Of the 97 patients, 30 were confirmed to have succumbed to 


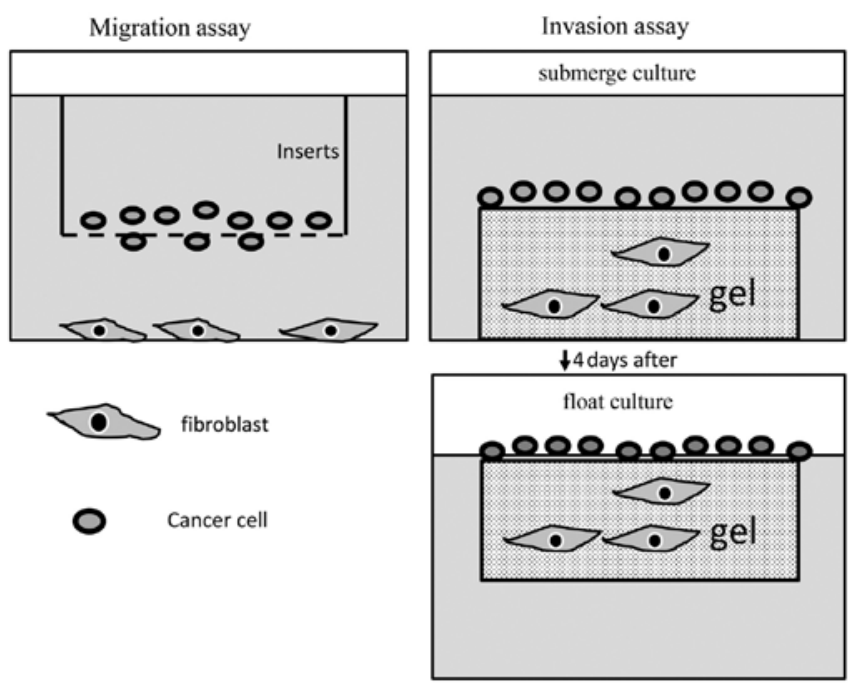

Figure 2. Migration and invasion assay schema. For migration assays, 24-well cell culture inserts with a pore size of $8 \mu \mathrm{m}$ (Falcon) were used. Inserts were placed in a 24 -well plate containing medium with fibroblasts. Cells in serum-free medium were placed in each insert. Migratory cells pass through the membrane and cling to the bottom side. Migratory cells were stained and counted with a VH analyzer (Keyence). For 3-dimensional organotypic cultures, immortalized fibroblasts were mixed with collagen and allowed to contract. Cancer cells were then plated, using a cloning ring. The cells were allowed $4 \mathrm{~h}$ to attach to the upper surface of the contracted collagen lattice. Cultures were submerged for 4 days and were then placed in 6-well inserts Cultures were raised to an air-liquid interface and cultured for 10-14 days.

Table II. Relationship between SMA expression and clinicopathological features.

\begin{tabular}{|c|c|c|c|c|c|c|}
\hline \multirow[b]{2}{*}{$\begin{array}{l}\text { Clinicopathological } \\
\text { features }\end{array}$} & \multirow[b]{2}{*}{$\mathrm{n}$} & \multicolumn{3}{|c|}{$\alpha$-SMA expression } & \multirow[b]{2}{*}{$\mathrm{r}$} & \multirow[b]{2}{*}{ P-value } \\
\hline & & Low & $\begin{array}{l}\text { Inter- } \\
\text { mediate }\end{array}$ & High & & \\
\hline Venous invasion & & & & & 0.33 & $<0.01$ \\
\hline v0 & 24 & 21 & 2 & 1 & & \\
\hline $\mathrm{v}+$ & 73 & 25 & 22 & 26 & & \\
\hline Nodal involvement & & & & & 0.18 & 0.02 \\
\hline $\mathrm{pN} 0$ & 46 & 28 & 10 & 8 & & \\
\hline $\mathrm{pN}+$ & 51 & 18 & 14 & 19 & & \\
\hline Recurrence & & & & & 0.2 & 0.01 \\
\hline- & 64 & 37 & 13 & 14 & & \\
\hline+ & 33 & 9 & 11 & 13 & & \\
\hline
\end{tabular}

$\mathrm{pN}+$, positive for pathological lymph node metastasis; $\mathrm{v}+$, positive for pathological venous invasion; $n$, number; $r$, correlation coefficient; SMA, smooth muscle actin; $\alpha$-SMA, $\alpha$-smooth muscle actin.

ESCC. More than half of the patients $(62 / 97,64 \%)$ presented with relatively early-stage disease (stage I-II according to the TNM classification) (17). Fig. 1 shows typical examples of tumors with low, intermediate and high SMA expression. The percentages of patients with low, intermediate and high $\alpha$-SMA expression were 47.4, 24.7 and $27.8 \%$, respectively. Clinicopathologically, $\alpha$-SMA expression correlated with
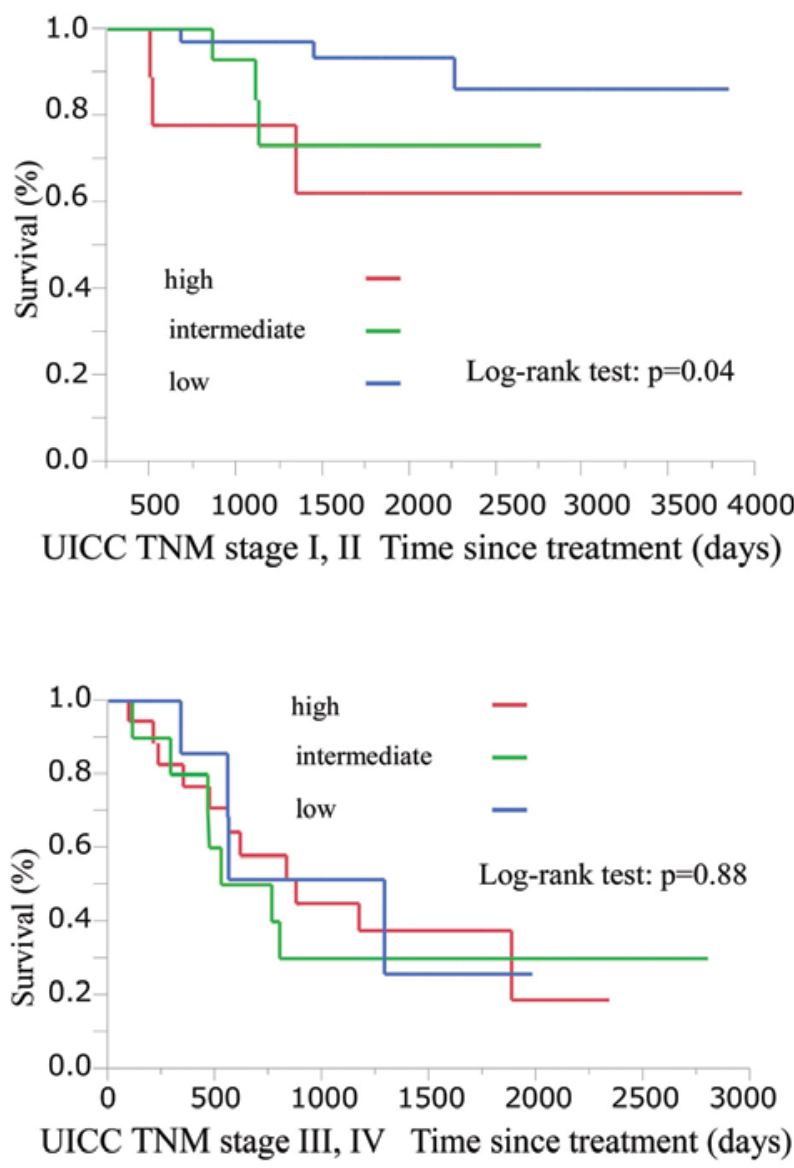

Figure 3. Kaplan-Meier survival curves according to $\alpha$-SMA expression. In stage I and II disease, survival rate correlated with $\alpha$-SMA expression (log-rank test, $\mathrm{p}=0.04$ ), whereas there was no correlation between survival rate and $\alpha$-SMA expression in stage III and IV disease. $\alpha$-SMA, $\alpha$-smooth muscle actin.

venous invasion, nodal involvement and recurrence $(p<0.01$, $\mathrm{p}=0.02$ and $\mathrm{p}=0.01$, respectively) (Table II). The mean survival time of the 97 patients with ESCC was 1,720 \pm 83 days.

Among patients with stage I and II disease, the KaplanMeier survival curves differed significantly according to $\alpha$-SMA expression $(p=0.04)$. In patients with advanced stage III and IV disease, however, there was no difference in survival according to SMA expression ( $\mathrm{p}=0.88)$ (Fig. 3).

Isolated human esophageal fibroblast promotes ESCC cell line progression in vitro and in vivo. We used in vitro and in vivo experimental systems to evaluate interactions between ESCC cells and stromal fibroblasts. In the migration assay, we compared stained images acquired from the bottom membrane of the cell culture inserts according to the presence and absence of fibroblasts. The presence of fibroblasts (HEF75) significantly promoted migration of KYSE150 and TE-11 cells (Fig. 4). For KYSE220, there was virtually no migration of cancer cells through the membrane in the absence of fibroblasts (data not shown). The KYSE150 and KYSE220 cell lines showed invasion into the extracellular matrix gel mixed with human immortalized esophageal fibroblasts (HEF75-hTERT), while cancer cells alone showed no such effect (Fig. 5). Finally, ESCC cells (TE-11 and KYSE220) 


\section{Migration assay}

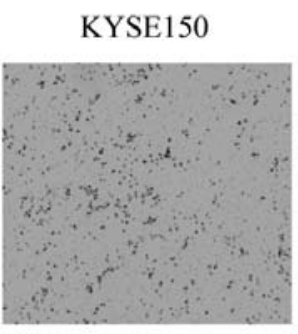

KYSE150+fib

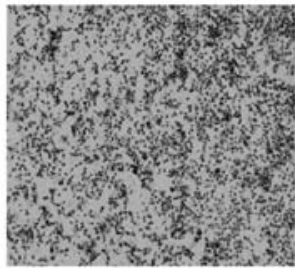

TE-11

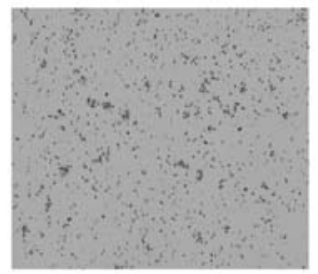

TE-11+fib

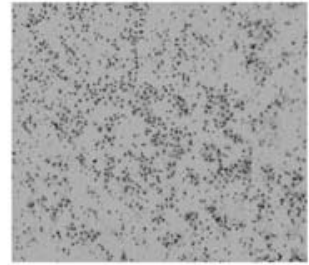

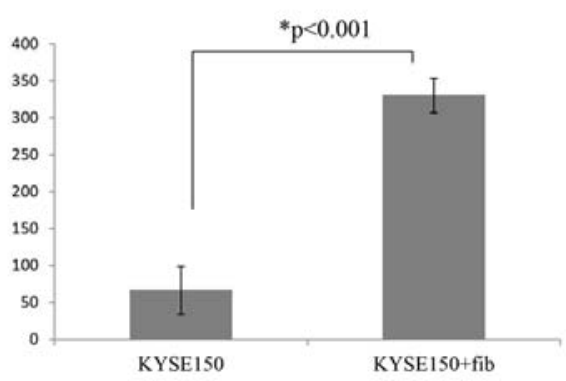

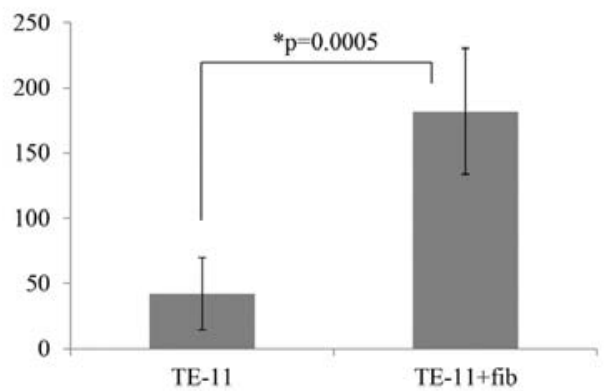

Figure 4. Migration assay. Comparison of stained images acquired from the bottom of the membranes of the cell culture inserts in the presence and absence of fibroblasts. The presence of fibroblasts (HEF75) significantly increased migration of specific cancer cells.

\section{Invasion assay}
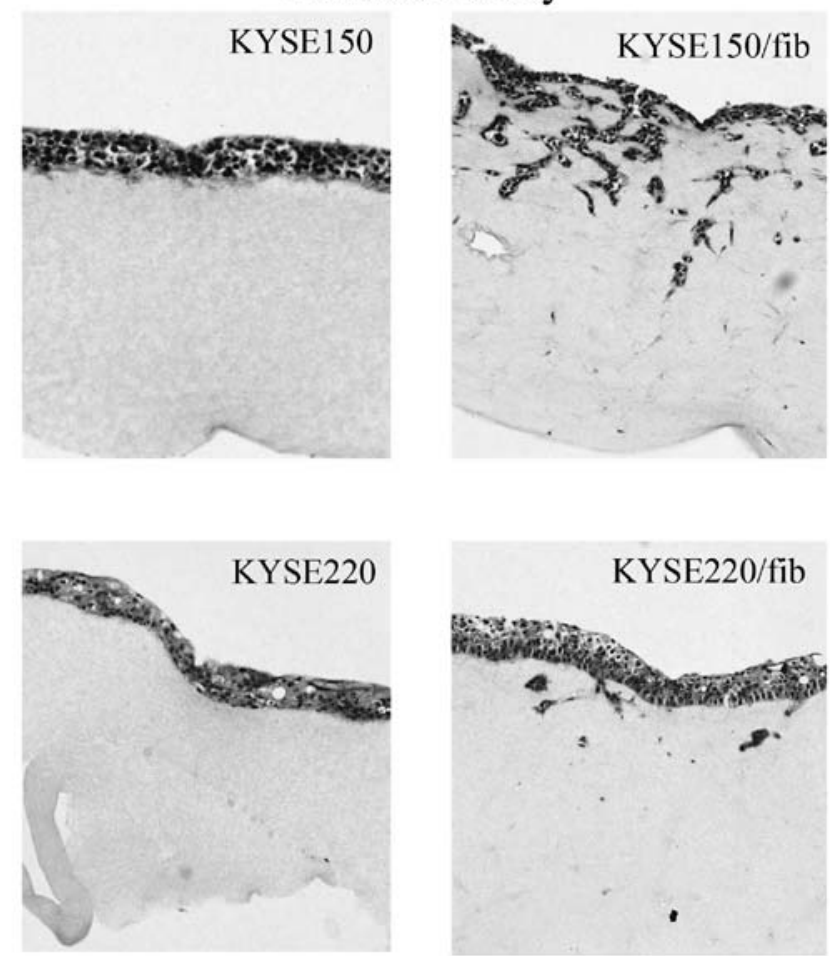

Figure 5. Invasion assay. Cultures were harvested by fixing in 10\% formaldehyde and were later embedded in paraffin. KYSE150 and KYSE220 cell lines invaded into the extracellular matrix gel mixed with human immortalized esophageal fibroblasts (HEF75-hTERT), while cancer cells alone did not.

alone or together with immortalized human esophageal fibroblasts (HEF75-hTERT) were suspended in PBS and injected subcutaneously into the flanks of the Nod/Scid mice to assess the effects of fibroblasts on tumorigenicity. Tumors developed in a fibroblast-dependent manner after the implantation of the two ESCC cell lines (Fig. 6).

\section{Discussion}

Cancer results from the accumulated effects of many genetic alterations, and the specific combination of changes is reflected in the unique characteristics of each tumor. However, the microenvironment of cancer cells has recently been shown to strongly influence the biologic properties of cancer (7). Activated fibroblasts in tumor stroma, referred to as CAFs, have been associated with poor outcomes in several types of carcinoma (9). $\alpha$-SMA is the most widely used marker of CAFs $(22,23)$. In the present study, we initially examined expression levels of $\alpha$-SMA in tumor stroma of resected ESCC specimens. Clinicopathologically, lymph node metastasis, venous invasion and recurrence were significantly related to $\alpha$-SMA expression levels. Furthermore, increased $\alpha$-SMA expression was associated with poorer outcomes in patients with earlier stage ESCC. In contrast, there was no relationship between $\alpha$-SMA expression and outcomes in patients with more advanced disease. These findings suggested that increased stromal $\alpha$-SMA expression may be a predictor of mortality in patients with earlier stage ESCC.

Next, we conducted migration and invasion assays to assess the effects of stromal fibroblasts. The presence of fibroblasts (HEF75) strongly promoted migration of KYSE150, KYSE220 and TE-11 cells (Fig. 4). Furthermore, the KYSE150 and KYSE220 cell lines invaded into the extracellular matrix gel mixed with human immortalized esophageal fibroblasts (HEF75-hTERT) (Fig. 5). These assays showed that isolated esophageal fibroblasts could promote cancer-cell migration and invasion. Tumor stroma has been suggested to play a critical role in the progression of human ESCC (24). Growth 

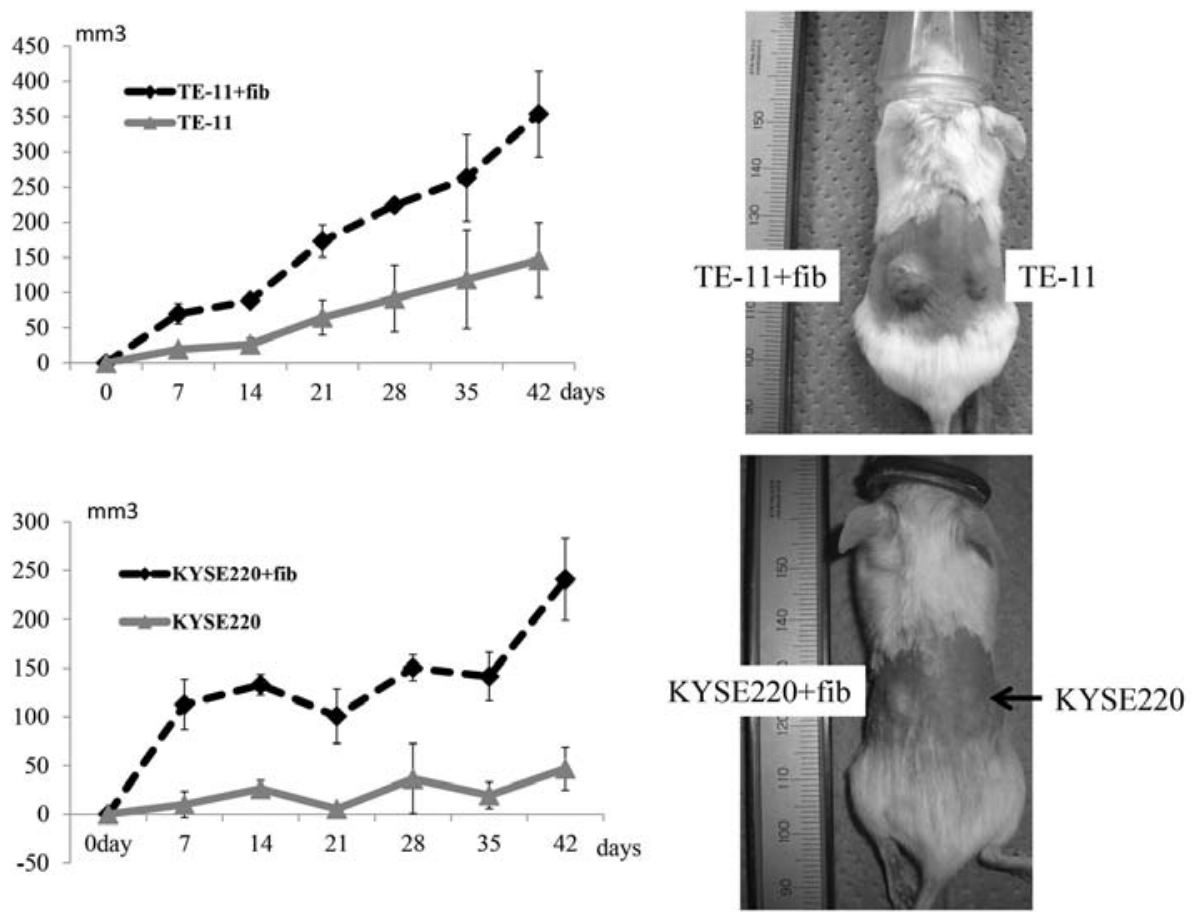

Figure 6. Co-injection into Nod/Scid mice. TE-11 cells plus fibroblasts and KYSE220 cells plus fibroblasts were co-transplanted subcutaneously in Nod/Scid mice. ESCC cells alone or together with HEF75-hTERT were suspended in PBS and injected subcutaneously into the flanks of the mice (two injection sites per mouse). A cancer cell suspension $\left(2 \times 10^{5}\right.$ cells/200 $\left.\mu \mathrm{l}\right)$ was injected subcutaneously into the right side of the mice and a suspension of $2 \times 10^{5}$ cancer cells plus $6 \times 10^{5} \mathrm{HEF} 75$-hTERT/200 $\mu \mathrm{l}$ into the left side of the mice. The mice were sacrificed after 6 weeks. We measured the minor axis and major axis and calculated the tumor volume as an oval sphere shape. The following formula was used to calculate tumor volume: Volume $=0.5236 \mathrm{ddD}$ ( $\mathrm{d}$, minor axis; $\mathrm{D}$, major axis). The data represent means \pm standard deviation of three independent experiments.

factors such as hepatocyte growth factor (HGF) and fibroblast growth factors (FGF) secreted by cancer stroma can promote ESCC development and progression (7,25-28). In the present study, growth factors and cytokines (29) secreted by isolated fibroblasts may have played an important role in cancer-cell migration and invasion. Gaggioli et al reported that fibroblasts may generate a track within the matrix that SCC cells then use to invade in organotypic culture model experiments (30). Not only paracrine systems induced by growth factors secreted by fibroblasts, but also the ability of fibroblasts to create tracks in the matrix may have promoted cancer-cell invasion in our organotypic assay. In vivo, fibroblasts may also have helped cancer cells grow in a fibroblast-dependent manner after the implantation of two ESCC cell lines (Fig. 6). We also subcutaneously transplanted HEF75 and HEF75-hTERT into the Nod/Scid mice and sacrificed the animals 2, 4, and 6 weeks after injection. Immunohistochemical studies of vimentin (clone V9; Dako), which does not react with cells of mice (31), showed that the survival periods of transplanted normal fibroblasts and immortalized fibroblasts were 2 and 4 weeks, respectively (data not shown). These findings suggested that interactions between ESCC cells and fibroblasts play a critical role in the relatively early period after co-transplantation. This hypothesis may be consistent with our finding that higher stromal $\alpha$-SMA expression was related to poorer survival in patients with earlier stage ESCC.

In conclusion, our data provide evidence that stromal fibroblasts and tumor cells interact to promote tumor progression in ESCC. In patients with earlier stage ESCC, $\alpha$-SMA may be a predictor of mortality. Our findings also suggest that inhibi- tion of paracrine systems related to fibroblasts and cancer cells may slow or reverse tumor progression.

\section{References}

1. Pisani P, Parkin DM, Bray F and Ferlay J: Estimates of the worldwide mortality from 25 cancers in 1990. Int J Cancer 83: 18-29, 1999.

2. Cook MB: Non-acid reflux: the missing link between gastric atrophy and esophageal squamous cell carcinoma? Am J Gastroenterol 106: 1930-1932, 2011.

3. Higuchi K, Koizumi W, Tanabe S, et al: Current management of esophageal squamous-cell carcinoma in Japan and other countries. Gastrointest Cancer Res 3: 153-161, 2009.

4. Chang CY, Cook MB, Lee YC, et al: Current status of Barrett's esophagus research in Asia. J Gastroenterol Hepatol 26: 240-246, 2011.

5. Hongo M, Nagasaki Y and Shoji T: Epidemiology of esophageal cancer: Orient to Occident. Effects of chronology, geography and ethnicity. J Gastroenterol Hepatol 24: 729-735, 2009.

6. Enzinger PC and Mayer RJ: Esophageal cancer. N Engl J Med 349: 2241-2252, 2003.

7. Mueller MM and Fusenig NE: Friends or foes - bipolar effects of the tumour stroma in cancer. Nat Rev Cancer 4: 839-849, 2004.

8. Radisky DC, Kenny PA and Bissell MJ: Fibrosis and cancer: do myofibroblasts come also from epithelial cells via EMT? J Cell Biochem 101: 830-839, 2007.

9. Marsh D, Suchak K, Moutasim KA, et al: Stromal features are predictive of disease mortality in oral cancer patients. J Pathol 223: 470-481, 2011.

10. De Wever O and Mareel M: Role of tissue stroma in cancer cell invasion. J Pathol 200: 429-447, 2003.

11. Liotta LA and Kohn EC: The microenvironment of the tumourhost interface. Nature 411: 375-379, 2001.

12. Surowiak P, Murawa D, Materna V, et al: Occurence of stromal myofibroblasts in the invasive ductal breast cancer tissue is an unfavourable prognostic factor. Anticancer Res 27: 2917-2924, 2007. 
13. Kellermann MG, Sobral LM, da Silva SD, et al: Myofibroblast in the stroma of oral squamous cell carcinoma are associated with poor prognosis. Histopathology 51: 849-853, 2007.

14. Tsujino T, Seshimo I, Yamamoto H, et al: Stromal myofibroblasts predict disease recurrence for colorectal cancer. Clin Cancer Res 13: 2082-2090, 2007.

15. Kalluri R and Zeisberg M: Fibroblasts in cancer. Nat Rev Cancer 6: 392-401, 2006.

16. Japanese Esophageal Society: Japanese Classification of Esophageal Cancer, tenth edition: part I. Esophagus 6: 1-25, 2009.

17. Sobin LH GM, Gospodarowicz MK and Wittekind CH (eds): International Union Against Cancer (UICC) TNM Classification of Malignant Tumors. 7th edition. Wiley-Blackwell, 2009.

18. Andl CD, Mizushima T, Nakagawa H, et al: Epidermal growth factor receptor mediates increased cell proliferation, migration, and aggregation in esophageal keratinocytes in vitro and in vivo. J Biol Chem 278: 1824-1830, 2003.

19. Underwood TJ, Derouet MF, White MJ, et al: A comparison of primary oesophageal squamous epithelial cells with HET-1A in organotypic culture. Biol Cell 102: 635-644, 2010.

20. Aoki S, Takezawa T, Uchihashi K, Sugihara H and Toda S: Non-skin mesenchymal cell types support epidermal regeneration in a mesenchymal stem cell or myofibroblast phenotype-independent manner. Pathol Int 59: 368-375, 2009.

21. Okawa T, Michaylira CZ, Kalabis J, et al: The functional interplay between EGFR overexpression, hTERT activation, and p53 mutation in esophageal epithelial cells with activation of stromal fibroblasts induces tumor development, invasion, and differentiation. Genes Dev 21: 2788-2803, 2007.

22. Erez N, Truitt M, Olson P, Arron ST and Hanahan D: Cancerassociated fibroblasts are activated in incipient neoplasia to orchestrate tumor-promoting inflammation in an NF- $\kappa \mathrm{B}$-dependent manner. Cancer Cell 17: 135-147, 2010.
23. Sugimoto H, Mundel TM, Kieran MW and Kalluri R: Identification of fibroblast heterogeneity in the tumor microenvironment. Cancer Biol Ther 5: 1640-1646, 2006.

24. Noma K, Smalley KS, Lioni M, et al: The essential role of fibroblasts in esophageal squamous cell carcinoma-induced angiogenesis. Gastroenterology 134: 1981-1993, 2008.

25. Yoshino M, Ishiwata T, Watanabe M, et al: Expression and roles of keratinocyte growth factor and its receptor in esophageal cancer cells. Int J Oncol 31: 721-728, 2007.

26. Ren Y, Cao B, Law S, et al: Hepatocyte growth factor promotes cancer cell migration and angiogenic factors expression: a prognostic marker of human esophageal squamous cell carcinomas. Clin Cancer Res 11: 6190-6197, 2005.

27. Grugan KD, Miller CG, Yao Y, et al: Fibroblast-secreted hepatocyte growth factor plays a functional role in esophageal squamous cell carcinoma invasion. Proc Natl Acad Sci USA 107: 11026-11031, 2010

28. Zhang C, Fu L, Fu J, et al: Fibroblast growth factor receptor 2-positive fibroblasts provide a suitable microenvironment for tumor development and progression in esophageal carcinoma. Clin Cancer Res 15: 4017-4027, 2009.

29. Lederle W, Depner S, Schnur S, et al: IL-6 promotes malignant growth of skin SCCs by regulating a network of autocrine and paracrine cytokines. Int J Cancer 128: 2803-2814, 2011.

30. Gaggioli C, Hooper S, Hidalgo-Carcedo C, et al: Fibroblast-led collective invasion of carcinoma cells with differing roles for RhoGTPases in leading and following cells. Nat Cell Biol 9: 1392-1400, 2007.

31. Bohn W, Wiegers W, Beuttenmüller M and Traub P: Speciesspecific recognition patterns of monoclonal antibodies directed against vimentin. Exp Cell Res 201: 1-7, 1992. 